\title{
REFLEXÕES SOBRE O JOGO NA EDUCAÇÃO INFANTIL
}

\author{
REFLECTIONS ON THE PLAY IN CHILD EDUCATION
}

DOI: $10.23926 / R P D .2526-2149.2020 . v 5 . n 2 . p 1342-1354 . i d 741$

\author{
Marcos Paulo Vaz de \\ Campos Pereira \\ Mestre em Ciências do \\ Movimento Humano \\ (UDESC) \\ Doutorando em Ciências do \\ Movimento Humano \\ (UDESC). \\ marcosp.pereira46@gmail,co \\ $\underline{\mathrm{m}}$
}

\section{Gelcemar Oliveira \\ Farias}

Doutora em Educação Física

(UFSC)

Professora adjunta na

Universidade do Estado de

Santa Catarina (UDESC).

fariasgel@hotmail.com
Resumo: O docente na educação infantil deve oportunizar ao educando atividades que enriqueçam a criatividade e a autonomia. Em meio a este contexto, o jogo importante fenômeno cultural e social contribui com o desenvolvimento humano. O objetivo deste artigo é apresentar uma reflexão sobre as características do jogo no contexto da educação infantil e sua valorização como importante recurso pedagógico. A metodologia utilizada se caracteriza como um ensaio teórico. Pode-se mencionar que o jogo é uma atividade livre, sendo delimitada por espaço, tempo e regras, além de ser imprevisível e fictício. Podendo ser utilizado como um recurso pedagógico na educação infantil, fase primordial de desenvolvimento do educando. Conclui-se, que o jogo enquanto recurso pedagógico pode ser considerado um meio adequado para contribuir no desenvolvimento integral do educando.

Palavras-chave: Jogo. Ensino. Aprendizagem.

\begin{abstract}
The teacher in early childhood education should provide opportunities for students to activities that enrich creativity and autonomy. Amid this context, the important cultural and social phenomenon play contributes to human development. The purpose of this article is to present a reflection on the characteristics of the play in the context of early childhood education and its appreciation as an important pedagogical resource. The methodology used is characterized as a theoretical essay. It can be mentioned that the play is a free activity, being limited by space, time and rules, besides being unpredictable and fictitious. It can be used as a pedagogical resource in early childhood education, the primary stage of development of the student. The play can be concluded as a pedagogical resource that can be considered an adequate means to contribute to the integral development of the student.
\end{abstract}

Keywords: Play. Teaching. Learning. 


\section{INTRODUÇÃO}

A educação infantil é uma das fases mais importantes do desenvolvimento humano, em consequência situações de aprendizagem devem ser frequentemente estimuladas pelos docentes em seus locais de ensino (FREIRE, 2002; KISHIMOTO, 2011). Vygotsky (1988) em sua teoria histórico-social expõe que para ocorrer a aprendizagem devem haver interações sociais, pelas quais o indivíduo aprende através do contato com seu ambiente e as pessoas que ali estão.

A aprendizagem é um processo deliberativo, intencional que ocorre devido às intervenções do docente (VYGOTSKY, 1988). Nesta etapa de desenvolvimento, é preciso adotar estratégias pedagógicas que correspondam às características dos educandos, propondo atividades educativas e lúdicas que explorem seu imaginário (KISHIMOTO, 2011; PEREIRA et al., 2016; PEREIRA; FARIAS 2020).

O jogo pode ser um recurso pedagógico adotado para subsidiar aspectos lúdicos e educativos. O jogo é uma atividade livre, dotado de alegria, de espaço, de tempo e de regras. Ele mostra-se imprevisível e favorece o fictício (CAILLOIS, 1990). Para conservar estas características do jogo e seus aspectos lúdicos e educativos, é significativo oportunizar a interação dos educandos com o jogo e com o contexto, isto é, utilizá-lo como um recurso pedagógico para ensinar os conteúdos propostos (PEREIRA et al., 2018).

O jogo ainda é marginalizado no contexto educacional, por motivos diversos: receio dos educadores em utilizar o jogo e perder o controle sobre os educandos; utilização do jogo como recompensa para ensinar os conteúdos; adoção do jogo sem uma finalidade pedagógica; tentativa de controlar a imprevisibilidade do jogo (CHÂTEAU, 1987; KISHIMOTO, 1994; BROUGÈRE, 1998; FREIRE, 2002). Por conseguinte, a criança afasta-se deste bem valioso, com implicações em seu desenvolvimento e o docente restringe sua prática pedagógica a estratégias que podem não condizer com a educação infantil.

O jogo é um fenômeno complexo e carece ainda de investigações mais amplas que explorem suas distintas manifestações. No cenário escolar, ele se apresenta como um conteúdo ou uma estratégia de ensino para se chegar ao conhecimento. Cabe ao docente compreender as características e as potencialidades pedagógicas do jogo as quais podem favorecer o aprendizado dos alunos na educação infantil, etapa da educação básica tão importante para o desenvolvimento humano (VYGOTSKY, 1988; FREIRE, 2002; PEREIRA et al., 2018).

De acordo com o cenário apresentado e com os aspectos pedagógicos da utilização do jogo em âmbito educacional e tendo em vista a necessidade de investigações que aprofundem a discussão sobre este fenômeno complexo, o objetivo deste artigo é apresentar uma reflexão 
sobre as características do jogo no contexto da educação infantil e sua valorização como importante recurso pedagógico.

\section{Metodologia}

Para a realização deste artigo, apresenta-se como fundamentação metodológica um ensaio teórico. Ensaios teóricos são fundamentais para apresentar, por meio da literatura, um cenário de investigação, bem como para, discutir e apresentar reflexões e opiniões de diferentes bases teóricas acerca do fenômeno investigado (MENEGHETTI, 2011). Adotou-se uma abordagem qualitativa, a qual consiste na exploração de referencial teórico para dar subsídios à investigação sobre o problema de pesquisa (CERVO; BERVIAN; SILVA, 2014).

Com relação aos procedimentos metodológicos, foram adotados, como referencial teórico, estudos que investigam o jogo em vários contextos como o da sociologia, da filosofia, da biologia, da psicologia, da matemática, da educação física, da pedagogia. Utilizaram-se livros e artigos científicos de autores que se debruçaram em investigar o jogo. O presente estudo tem caráter bibliográfico, servindo-se de material impresso e on-line.

\section{INTERFACES ENTRE A DOCÊNCIA O EDUCANDO E O JOGO}

Em vista das indagações que envolvem o fenômeno do jogo, a presente discussão pondera as dificuldades em definir suas áreas de estudo, sua adoção na escola e na educação infantil, sua utilização como recurso pedagógico. Ressalta-se que esta investigação delimita-se, na abordagem do jogo por meio de autores que o investigaram em diversas áreas do conhecimento, porém com foco na educação, tendo como contexto o ambiente escolar.

O jogo é um fenômeno polissêmico, definido de acordo com sua utilização. Compreender a palavra jogo requer entender sua lógica semântica e seus mais variados empregos (BROUGÈRE, 1998). Para entender a lógica semântica que conceitua o jogo em seus contextos e para compreendê-lo, é fundamental explorar a linguagem e contextualizar seu empregado (BROUGÈRE, 1998; FREIRE, 2002).

O dicionário Houaiss (2009) apresenta 18 significados diferentes ao termo, em destaque: atividade com finalidade de diversão, atividade submetida às regras e brincadeira, jogo de peças, conjunto de componentes. Esta gama de significados linguísticos dá uma ideia da amplitude semântica da palavra jogo (CAILLOIS, 1990). Cada significado possui um objetivo, visando diferenciar seu uso (WITTGENSTEIN, 1999). 
O jogo não pode ser definido por um único termo, considerando seus vários significados (HUIZINGA, 2000) e seus variados contextos, definir o jogo torna-se, portanto, complexo. Scaglia (2003) discorre que o jogo não deve ser definido somente pela linguagem, mas também pelo contexto, sendo conceituado conforme seus diversos ambientes.

A complexidade em investigar o jogo leva a percorrer diversas áreas do conhecimento, tais como sociologia, filosofia, biologia, psicologia, matemática, educação física, pedagogia, as quais visam compreendê-lo (SCAGLIA, 2007). Segundo a psicologia, através do jogo consegue-se estudar aspectos motores, afetivos, sociais e morais da criança, conforme sua fase de desenvolvimento, seu contexto e a formação de sua personalidade (CHATEAU, 1987; PIAGET, 1990).

De acordo com a filosofia, como expressa Wittgenstein (1999), o jogo de linguagem apresenta que os jogos relacionam-se por suas semelhanças, em uma analogia com o conceito de família, em que, por suas semelhanças, os grupos surgem e cruzam-se em uma teia. $\mathrm{O}$ autor exemplifica com os jogos de tabuleiro, observando que, por suas características e semelhanças, eles, formam uma 'família' de jogos de tabuleiro, com possibilidade de serem formadas inúmeras famílias de outros jogos que tenham algumas semelhanças, embora possuam significados distintos.

No contexto da educação física, o jogo pode ser utilizado como conteúdo ou como metodologia de ensino (FREIRE, 2002; FREIRE; SCAGLIA, 2003; SCAGLIA, 2007). Como conteúdo, sua gama de atividades é representada, entre outros, por jogos populares, folclóricos, tradicionais (FREIRE; SCAGLIA, 2003; VENÂNCIO; FREIRE, 2005; ZIMMERMANN; SAURA, 2014). Como metodologia, pode ser utilizado para ensinar, entre outros, esportes, dança, ginástica (FREIRE; SCAGLIA, 2003; SCAGLIA, 2007; PEREIRA et al., 2016).

No campo da pedagogia, o jogo, conforme investigado por Kishimoto (1994; 2014), desempenha um importante papel na educação. Ele é fundamental para o desenvolvimento integral da criança, por estimular suas habilidades físicas e apresentar condutas morais e sociais. O jogo assume variados significados, podendo ser compreendido por suas semelhanças. Corroborando Wittgenstein (1999), a citada autora apresenta uma família de jogos, na qual os pontos que se relacionam são: liberdade do jogador; ação lúdica; prazer ou desprazer; regras implícitas ou explícitas; representação do real; presença de tempo e espaço; e não seriedade. Pela interligação destas características forma-se a grande família dos jogos. 
Além da investigação sobre o fenômeno polissêmico do jogo, autores visam também defini-lo ou compreendê-lo em suas diversas características e manifestações em contextos distintos (social, cultural e educacional), contribuindo para evidenciar sua complexidade.

Huizinga (2000) menciona que alguns autores utilizam respostas parciais para tentar solucionar o problema do jogo e o analisam como uma atividade física e biológica. Em consequência, o jogo prevalece como uma atividade voluntária e temporária, que apresenta tempo, espaço e regras predefinidas. O jogo possui características fundamentais como liberdade para a suspensão da realidade, sentimentos de tensão e incerteza, intensa absorção dos jogadores.

Caillois (1990) define o jogo como uma atividade livre, justificada à qual o jogador não deve ser obrigado, pois o jogo perderia seu bem mais valioso, a alegria. Esta atividade caracteriza-se por ser delimitada por espaço e tempo; incerta, pois o resultado e o desenrolar não podem ser determinados; improdutiva, sem gerar algum bem ou riqueza; regulamentada por regras; fictícia, pois estipulada por uma suspensão da realidade. O mesmo autor apresenta os múltiplos tipos de jogos, por exemplo, de azar; ao ar livre; de construção; de sociedade; de destreza.

Há uma ampla diversidade de jogos que podem ser classificados pelas categorias agôn, alea, mimicry, ilinx. Cada uma apresenta características peculiares, no entanto para defini-las prevalecem os conceitos expressos pelo autor anteriormente citado.

Conforme Caillois (1990), agôn são jogos de competição, de duelo, de torneio, por exemplo, corridas, lutas, futebol, para os quais os jogadores devem treinar a fim de obter o melhor proveito. Alea são jogos de acaso, de sorte, de apostas, por exemplo, de roleta e de cara ou coroa. A alea é diferente da agôn, pois a vitória advém pela sorte, não adiantando realizar um treinamento para obter melhor proveito. A mimicry corresponde à suspensão da realidade, ao faz de conta, em que se explora o imaginário, por exemplo, teatro ou brincar de boneca. A ilinx compreende os jogos de vertigem, de espasmos, de emoções, como a corda bamba ou brincadeiras de roda.

Esta classificação de Caillois (1990) apresenta uma hierarquia, em que reinam dois princípios antagônicos: paidia e ludos. $\mathrm{O}$ autor assim diferencia os tipos de jogos e os sistematiza conforme as características destes dois pólos que estejam mais presentes.

O princípio da paidia pode ser compreendido como diversão, turbulência e fantasia. A paidia está presente na alegria em geral, predominando em uma das extremidades dos jogos. O princípio ludos encontra-se na extremidade oposta, em que a alegria é absorvida, não 
totalmente, inclui jogos de regras mais convencionais, nos quais o prazer em alcançar o objetivo é dificultado, sendo requeridas habilidades e múltiplas tentativas. O ludos pode complementar a paidia, mas somente na tentativa de organizar a alegria, equilibrar a diversão.

Huizinga (2000) define o jogo como uma atividade livre, em um contexto fictício, contendo: espaço e tempo predefinidos. Caillois (1990) faz uma crítica a tal autor, ao dizer que o divertimento e a alegria devem estar presentes no jogo. Caillois (1990) compreende que estes elementos são fundamentais para que o jogo exista e prevaleça, não só em relação às crianças, mas para qualquer um que queira entrar no domínio do jogo.

Ambos os autores citados entram em consonância sobre os limites do jogo - frivolidade e êxtase. Frivolidade é quando o jogador não leva a sério o jogo, o tornando banal e o desprezando. Êxtase é quando o jogador sente-se intensificado por emoções. A frivolidade e o êxtase são pólos antagônicos que limitam o jogo, qualquer jogador que ultrapasse estes limites deixa de jogar, os participantes devem tentar respeitar estes limites para que o jogo aconteça plenamente (CAILLOIS, 1990; HUIZINGA, 2000).

Outro ponto em comum entre os autores referidos é a apresentação do trapaceiro (assim denominado por Caillois) ou do desmancha prazeres (assim denominado por Huizinga). Estas figuras representam aquele que desiste do jogo, que rouba, que não respeita as regras, que burla. Este tipo não tem espaço no jogo. Quando o trapaceiro ou o desmancha prazeres aparece, o jogo é desrespeitado e não ocorre, pois as regras estabelecidas devem ser respeitadas plenamente pelos participantes (CAILLOIS, 1990; HUIZINGA, 2000).

Em relação ao desenvolvimento humano, o jogo configura-se como um meio para ter a percepção do desenvolvimento integral da criança, devido ao estímulo a aspectos motores, afetivos e cognitivos (CHÂTEAU, 1987). Château (1987), ao investigar o jogo, evidenciou sua contribuição para o desenvolvimento integral da criança quando joga. No jogo a personalidade infantil emerge, sendo impossível esconder sentimentos e habilidades. Neste viés, pode-se considerar o jogo como uma espécie de teste de personalidade.

Château (1987) explica que o jogo tem que ser sério, sempre com regras que podem ser ajustadas, sendo um treinamento involuntário para a vida real, nele se faz o movimento entre realidade e ficção (faz de conta). A possibilidade de ter a percepção total da criança pode ser observada quando ela joga sozinha. Château (1987) denomina esta atividade de jogo solitário, constituindo a fuga da criança do mundo dos adultos. Nele a criança expressa-se por múltiplas linguagens, com ritmo e repetição, com estilo próprio, pois cada uma joga diferente das outras. 
O mesmo autor acrescenta que o jogo atrai a criança. Um jogo solitário pode logo reunir inúmeros participantes e deixar de ser solitário, pois no jogo prevalece a interação. O jogo, mesmo com o passar do tempo, continua a possibilitar o desenvolvimento infantil por meio da ludicidade (CHÂTEAU,1987).

Piaget (1990) também expõe a importância do jogo para o desenvolvimento da criança, pois o jogo é uma representação simbólica que a satisfaz. Ele pode ser classificado de acordo com a fase de desenvolvimento e seu contexto. A complexidade dos jogos mostra-se fundamental para que a criança alcance seu desenvolvimento integral. Para que isso ocorra, é preciso jogar e, para que a criança jogue, é necessário estimulá-la e propiciar-lhe ambientes de jogo voltados à ficção (ao faz de conta), oportunizando que a imaginação infantil funcione.

A complexidade do jogo é justificada por Brougère (1998), ao dizer que é preciso compreender o jogo que se joga. Um jogo difere do outro por ser mais ou menos complexo. Os jogos podem conter inúmeras semelhanças, porém um nunca será igual ao outro. O jogo depende dos participantes, deve ter sentido e significado, simular o real e, principalmente, seduzir a criança para que ela jogue plenamente.

Brougère (1998) corrobora outros autores quando fala sobre a seriedade do jogo, pois, por mais simples (menos complexo) que ele seja, não deixa de ser sério para a criança. $O$ princípio de seriedade manifesta-se no prazer do sucesso quando o participante alcança seu objetivo e prepara-se para novos desafios (um jogo mais complexo) (CHÂTEAU, 1987; BROUGÈRE, 1998; FREIRE, 2002; SCAGLIA, 2007; PEREIRA et al., 2018).

Freire (2002), investigou o jogo como uma necessidade básica da criança. Ressalta-se que alguns autores e investigadores do fenômeno jogo deveriam partir da criança para compreendê-lo e não atribuir-lhe características básicas e fragmentadas na tentativa de definilo. Para Freire (2002), a constante fragmentação para analisar cada parte do jogo não possibilita sua compreensão, mas oferece apenas uma mera ilusão do que ele realmente é. O estudo do jogo é, portanto, complexo.

Freire (2002) diz que o jogo deve ser compreendido em sua totalidade, por suas manifestações, por seu contexto. O mesmo autor denomina "nicho do jogo" onde o jogo ocorre (seu ambiente), devendo envolver desafios, prazer, desequilíbrio, decisões, diversidade de situações, imprevisibilidade.

O nicho do jogo, ao qual Freire (2002) refere-se, justifica-se quando o jogador a ele se entrega por completo e com satisfação. Scaglia (2003) denomina estado de jogo o ato de jogar que move o participante a superar os desafios aos quais é submetido, estimulando sua 
criatividade e sua autonomia. A imprevisibilidade está permanentemente presente no jogo, pois não se pode prever o que acontecerá.

O ambiente de jogo gera o risco, o acaso, a tensão, o desequilíbrio, a imaginação e o desejo de jogar, o que pode ocasionar o sentimento de conquista, embora ganhando ou perdendo o jogo continua. As manifestações do jogo surgem quando se pratica esporte, se luta, se faz ginástica e também nas brincadeiras (FREIRE; SCAGLIA, 2003).

Ao falar do jogo no contexto educacional, Brougère (1998) o apresenta como marginalizado, que não é levado a sério, sendo utilizado de maneira indevida pelos educadores, empregado como mera distração, como algo recreativo, sem um fim pedagógico, sem um significado (KISHIMOTO, 1994; FREIRE, 2002). Uma das oposições ao jogo na escola advém do medo dos docentes de nele perderem o controle sobre os educandos, no entanto não se deve negar o jogo à criança, pois negar-lhe o jogo é negar sua infância (CHÂTEAU, 1987; KISHIMOTO, 1994; FREIRE, 2002; SCAGLIA, 2007).

O jogo com fins pedagógicos, sendo levado a sério e valorizado pelos educadores, respeitando a vontade dos educandos, cumpre papel imprescindível no desenvolvimento integral da criança. (KISHIMOTO, 1994; 2014). As contribuições deste tipo de jogo são vastas: interação entre os educandos; superação das dificuldades; aula centrada no aluno; desenvolvimento da criatividade; aumento da autonomia para resolver as situações-problema que aparecem com liberdade de escolha; consideração do conhecimento prévio; manutenção do que foi aprendido; elaboração coletiva de regras; desenvolvimento de habilidades motoras, socioafetivas e cognitivas pelo confronto com problemas que emergem durante o jogo (CHÂTEAU，1987; CAILlOIS，1990; KISHIMOTO，1994; 2014; BROUGÈRE，1998; HUIZINGA，2000; FREIRE，2002; FREIRE; SCAGLIA， 2003; SCAGLIA， 2007; LEONARDO; SCAGLIA; REVERDITO, 2009; PEREIRA et al., 2018).

No ambiente de jogo predominam os desafios e o educando tem que procurar recursos para resolvê-los. Há, por exemplo, a sempre presente representação, quando, ao imitar personagens e símbolos, a criança transporta-se a mundos imaginários. A imprevisibilidade encontra-se a todo o momento neste tipo de cenário, pois as tomadas de decisão e as mudanças contínuas no ambiente não são determinadas previamente. $\mathrm{O}$ desequilíbrio é um excelente exemplo desta situação, visto que, por tirar o educando de seu equilíbrio natural, o conduz a um mundo onde terá de interagir e ser criativo para solucionar as situações-problema às quais estará submetido (FREIRE, 2002; SCAGLIA, 2007). 
Este ambiente, que proporciona aproximações entre o contexto e as interações do educando com o jogo estabelecido, atribui responsabilidade também ao educador, a quem cabe aumentar a complexidade do jogo à medida que os problemas encontrados vão sendo resolvidos (FREIRE, 2002).

O ambiente de jogo apresenta complexidade em cada um de seus elementos, portanto a compreensão das diversas características pode gerar adaptações, diminuir a complexidade, estimular a criatividade e a autonomia. Neste meio, torna-se possível observar a personalidade de quem joga e realizar intervenções quando o aluno extrapola os limites fixados (SUITS, 1967).

Ao ser utilizado, o jogo é sistematizado através da representação simbólica feita pelo educando. De acordo com Vygotsky (1988), torna-se necessária a reflexão sobre o jogo de faz de conta como possibilidade de ensino, o qual desperta a imaginação da criança e trabalha com significados culturais do grupo social ao qual ela pertence (FREIRE, 2002; SCAGLIA, 2007; KISHIMOTO, 2011). A representação simbólica deve se inserir em um ambiente no qual o ensino e a aprendizagem possam associar-se à dimensão complexa do jogo e atingir os objetivos educacionais propostos (SCAGLIA, 2007; KISHIMOTO, 2011).

O jogo de faz de conta apresenta inúmeros fins pedagógicos: interação entre seus praticantes; consideração do conhecimento prévio do educando; desenvolvimento de habilidades motoras e cognitivas, através situações-problema que vão surgindo; liberdade de escolha, manifestada na opção por determinadas respostas; estímulo à criatividade (VYGOTSKY; COLE, 1991; FREIRE, 2002; SCAGLIA, 2007; KISHIMOTO, 2011; ZIMMERMANN; SAURA, 2014; PEREIRA et al., 2019).

Estes benefícios auxiliam no desenvolvimento da criança. Nos jogos de faz de conta sistematizados, deve-se observar se eles correspondem aos conteúdos que se pretende desenvolver, bem como buscar respaldo nas dimensões atitudinal, conceitual e procedimental destes mesmos conteúdos. A sistematização dos conteúdos, utilizando o jogo de faz de conta como estratégia pedagógica, deve se respaldar na compreensão de mundo do educando, em seus pensamentos e em suas escolhas (BRASIL, 1998; FREIRE, 2002; PEREIRA et al., 2019).

A organização curricular, com apoio no jogo como estratégia pedagógica, pode apresentar uma função utilitária, porém o equilíbrio entre as funções pedagógicas e lúdicas direciona o docente a sempre visar ao processo de ensino e de aprendizagem. O jogo seduz a criança devido à sua ludicidade e, por suas funções pedagógicas, contribui para seu 
desenvolvimento integral (KISHIMOTO, 2011; PEREIRA; FARIAS, 2020; SILVA; LORENCINI JUNIOR, 2020).

Na educação infantil, o docente pode utilizar o jogo como um recurso pedagógico para ensinar conteúdos primordiais para o desenvolvimento das crianças que estão em formação. Conforme mencionam os documentos norteadores da educação infantil no Brasil, cabe ao docente oportunizar aos educandos o desenvolvimento de suas capacidades, mediante o jogar e por meio dos conteúdos previstos para a educação infantil (currículo voltado aos saberes que fazem parte do patrimônio cultural da criança) (BRASIL, 1998; 2006; 2009; 2010).

A educação infantil - primeira etapa da educação básica - tem como finalidade o desenvolvimento integral da criança. Nessa etapa o jogo torna-se um direito do aluno (BRASIL, 1998). Cabe ao docente adequar os conteúdos por meio do jogo, respeitando a fase de desenvolvimento própria da educação infantil (PEREIRA et al., 2019).

Piaget (1990) apresenta possibilidades de jogos que podem auxiliar o docente no processo pedagógico como os de exercício, os simbólicos e os de regras, sendo requeridos sua diversificação e o respeito ao ambiente cultural da criança. Cada tipo de jogo apresenta características determinantes para estimular o educando. Na educação infantil, é importante que o docente oportunize, no dia a dia, o ambiente de jogo, em sala de aula, em ambientes diversificados dentro da escola ou fora dela (parques, praças, entre outros).

Tratando de jogos para o contexto da educação infantil, Vygotsky (1988) apresenta o jogo imaginário como uma representação social da vida, por exemplo a criança brincando de mamãe e filhinha, de escolinha ou representando outros contextos por ela vivenciados. O docente, nas aulas na educação infantil, pode utilizar este tipo de jogo para a valorização do ambiente cultural da criança e para enriquecer sua compreensão de mundo.

Portanto, o jogo apresenta inúmeras definições e características, sendo objeto de estudo de diversas áreas do conhecimento. Ele contribui significativamente para o desenvolvimento integral do educando, abrangendo habilidades motoras, socioafetivas e cognitivas. O jogo está presente na educação como um recurso pedagógico, colaborando com a prática docente ao potencializar o processo de ensino e de aprendizagem.

\section{CONSIDERAÇões FinAIS}

O atual cenário da educação infantil requer propostas que explorem o universo imaginário do educando. Assim, torna-se importante utilizar o jogo como uma estratégia de ensino, sendo balizado e sistematizado pelas dimensões dos conteúdos. O jogo possibilita 
nortear a prática docente, permitindo ao educador elaborar aulas diversificadas nesta tão importante fase do desenvolvimento das crianças.

O jogo oportuniza relacionar os conteúdos conforme seus níveis de complexidade, à medida que a criança vai resolvendo as situações emergentes. O jogo como recurso pedagógico explora a criatividade e a autonomia, devido à sua imprevisibilidade; permite a liberdade de expressão; respeita o conhecimento prévio; contribui para a formação integral.

Sugere-se para outros estudos acerca da temática, a abordagem de conteúdos propostos para a educação infantil, que ficaram à margem deste ensaio. Há possibilidade de estender semelhante discussão aos demais níveis de ensino (fundamental), e aprofundar a discussão sobre propostas pedagógicas na graduação e em formações continuadas de docentes.

\section{REFERÊNCIAS}

BRASIL. Diretrizes curriculares nacionais para a educação infantil. Ministério da Educação. Secretaria de Educação Básica. Secretaria de Educação Básica. - Brasília: MEC, SEB, 2010.

BRASIL. Indicadores da Qualidade na Educação Infantil. Ministério da Educação/Secretaria da Educação Básica - Brasília: MEC/SEB, 2009.

BRASIL. Parâmetros nacionais de qualidade para a educação infantil. Ministério da Educação. Secretaria de Educação Básica - Brasília. DF, 2006.

BRASIL. Referencial curricular nacional para a educação infantil. Ministério da Educação e do Desporto, Secretaria de Educação Fundamental. — Brasília: MEC/SEF, 1998.

BRASIL. Parâmetros Curriculares Nacionais. Secretaria de Educação Fundamental: Educação Física. Brasília: MEC /SEF, 1998.

BROUGÈRE, Gilles. Jogo e Educação. Porto Alegre: Artmed, 1998.

CAILLOIS, Roger. Os jogos e os homens: a máscara e a vertigem. Lisboa: Cotovia, 1990. CERVO, Amado; BERVIAN, Pedro; SILVA, Roberto. Metodologia Científica. São Paulo: Pearson Prentice Hall, 2014.

CHÂTEAU, Jean. O jogo e a criança. São Paulo: Summus, 1987.

FREIRE, João Batista. O Jogo entre o riso e o choro. São Paulo: Autores Associados, 2002. FREIRE, João Batista; SCAGLIA, Alcides José. Educação como prática corporal. São Paulo: Scipione, 2003.

HOUAISS, Antônio. Dicionário Houaiss da língua portuguesa - Rio de Janeiro: Objetiva, 2009. 
HUIZINGA, Johan. Homo Ludens. 4 ed. São Paulo: Perspectiva, 2000.

KISHIMOTO, Tizuko Morchida. Jogos infantis: o jogo, a criança e a educação. Petrópolis: Vozes, 2014.

KISHIMOTO, Tizuko Morchida. O brincar e suas teorias. Cengage Learning. São Paulo, 2011.

KISHIMOTO, Tizuko Morchida. O jogo e a educação infantil. São Paulo: Cengage Learning, 1994.

LEONARDO, Lucas; SCAGLIA, Alcides José; REVERDITO, Riller. O Ensino dos Esportes Coletivos: Metodologia pautada na Família dos Jogos. Motriz, Rio Claro, v. 15, n. 2, p. 236246, 2009.

MENEGHETTI, Francis Kanashiro. O que é um ensaio teórico. Revista de administração contemporânea, São Paulo, v.15, n. 2, p. 320-332, 2011.

PEREIRA, Marcos Paulo Vaz de Campos; CIRINO, Cirino; MILAN, Fabrício João; RESENDE, Rui; FARIAS, Gelcemar Oliveira. Reflexões Sistêmicas do Jogo: Contribuições para a Educação Física, Journal of Sport Pedagogy and Research, Maia, v. 4, n. 3, p.60-64, 2018.

PEREIRA, Marcos Paulo Vaz de Campos; FARIA, José Ronivan; OLIVEIRA, Adriano Olimeira; MILAN, Fabrício João; CUNHA, Virginia; FARIAS, Gelcemar Oliveira. Educação física infantil e o jogo de faz de conta como estratégia pedagógica. Caderno de Educação Física e Esporte, Marechal Rondon, v. 17, n. 2, p. 1-8, 2019.

PEREIRA, Marcos Paulo Vaz de Campos; FARIAS, Gelcemar Oliveira; CIRINO, Carol; SCAGLIA, Alcides José. O jogo como estratégia pedagógica para o ensino da Educação Física escolar no $5^{\circ}$ ano do ensino fundamental I. Corpoconsciência, São Paulo, v. 20, p. 1-8, 2016.

PEREIRA, Marcos Paulo Vaz de Campos; FARIAS, Gelcemar Oliveira. Professores de educação física e o jogo: reflexões no contex to escolar Corpoconsciência, São Paulo, v. 24, n. 2, p. 82-90, 2020.

PIAGET, Jean. A formação do símbolo na criança: imitação, jogo e sonho / imagem e representação. Rio de Janeiro: LTC, 1990.

SCAGLIA, Alcides José. Referencial Curricular da Educação básica das Escolas Públicas Municipais de Franca, Franca SP, 2007.

SCAGLIA, Alcides José. O futebol e os jogos/brincadeiras de bola com os pés: todos semelhantes, todos diferentes. 2003. 164f. Campinas: Tese (Doutorado em Educação Física). Universidade Estadual de Campinas, Campinas, 2003.

SILVA, Diogo; LORENCINI JUNIOR, Álvaro. O docente e sua constante reconstrução de saberes: o jogo como ferramenta de ressignificação de sua prática. Revista Prática Docente, Confresa, v. 5, n. 1, p. 289-305, 2020. 
SUITS, Bernard. What is a game? Philosophy of Science, Chicago, v. 34, n. 2, p. 148-156, 1967.

VENÂNCIO, Silvana; FREIRE, João Batista. O jogo dentro e fora da escola. Campinas: Autores Associados, 2005.

VYGOTSKY, Lev Semyonovich. Aprendizagem e Desenvolvimento Intelectual na Idade Escolar: Linguagem, desenvolvimento e aprendizagem. São Paulo: Ícone, 1988.

VYGOTSKY, Lev Semyonovich; COLE, Michel. A formação social da mente: o desenvolvimento dos processos psicológicos superiores. São Paulo: Martins Fontes, 1991.

WITTGENSTEIN, Ludwig. Investigações Filosóficas. Nova cultural, 1996.

ZIMMERMANN, Ana Cristina; SAURA, Soraia Chung. Jogos tradicionais. São Paulo: Pirata, 2014.

Recebido em: 1 de junho de 2020.

Aprovado em: 24 de agosto de 2020. 